\title{
Incidence of Postoperative Nausea and Vomiting in Dr. Hasan Sadikin General Hospital Bandung Period May to October 2013
}

\author{
Aisyah Ummu Fahma, ${ }^{1}$ Iwan Fuadi, ${ }^{2}$ Jimmy Setiadinata ${ }^{3}$ \\ ${ }^{1}$ Faculty of Medicine, Universitas Padjadjaran, ${ }^{2}$ Department of Anesthesiology and Intensive \\ Care Faculty of Medicine Universitas Padjadjaran/Dr. Hasan Sadikin General Hospital Bandung, \\ ${ }^{3}$ Department of Anantomy, Cell Biology and Physiology Faculty of Medicine Universitas \\ Padjadjaran
}

\begin{abstract}
Background: Postoperative nausea and vomiting (PONV) is common complication in patients undergoing surgery with anesthesia. The incidence of PONV is ranging between $20 \%$ and $30 \%$. Despite many other studies about PONV in other regions, the descriptive data about PONV in Dr. Hasan Sadikin General Hospital Bandung is still unknown. The aim of this study was to determine the incidence of PONV in Dr. Hasan Sadikin General Hospital Bandung.

Methods: This descriptive study used a cross-sectional method. As many as 521 medical records in Departement of Anesthesiology and Intensive Care Dr. Hasan Sadikin General Hospital Bandung from May 5th to October 31st 2013 were reviewed. The subjects were taken by using total sampling technique. Data collected were gender, age, type of surgery, type of anesthesia, duration of surgery, administration of nitrous oxide, and administration of neostigmine.

Results: Of 521 patients, the incidence of PONV was 20.5\%. Female had higher incidence of PONV than male. Postoperative nausea and vomiting was the most frequent in the age category 6-20 years old. The Ear Nose and Throat (ENT) surgery was revealed as surgery with the highest incidence. Regional anesthesia had a higher incidence than general anesthesia. Operation lasting 181-210 minutes was considered as category which PONV mostly occured. Patients receiving nitrous oxide were more likely to experience PONV, and patients who were given neostigmine as muscle relaxant had lower incidence of PONV compared to those who were not.

Conclusions: The incidence of PONV was similar to the study presumed earlier and this may influenced by many factors including patients, surgical, and aenesthtical factor. [AMJ.2017;4(1):58-63]
\end{abstract}

Keywords: Anesthesiology, incidence, postoperative nausea, vomiting.

\section{Introduction}

Postoperative nausea and vomiting (PONV), is defined as nausea and/or vomiting occuring within 24 hours after surgery. The PONV is a common problem following surgery and anesthesia and it is anesthesiology's "big little problem". Some efforts are focused on strategies to reduce the frequency of this problem. Nausea is an unpleasant sensation in the epigastrium that is associated with an urge to vomit while vomiting is the forceful expulsion of gastric contents. Avoiding PONV becomes the main priority for doctors and patients. PONV is still a big problem, besides dissatisfaction and discomfort of the patient and healthcare staff, medical risks such as increased abdominal pressure, increased central venous pressure, aspiration of gastric contents, sympathetic nervous system response with increasing blood pressure and heart rate as well as parasympathetic responses producing bradycardia and hypotension. It also results in increased morbidity, prolonged Post Anesthesia Care Unit stays and increased cost related to length of hospital stay. Most patients consider that nausea and vomiting is more disturbing than the operation itself. ${ }^{1-5}$

Nausea and vomiting in the postoperative period occurs in $20 \%$ to $30 \%$ of patients. In $10 \%$

Correspondence: Aisyah Ummu Fahma, Faculty of Medicine, Universitas Padjadjaran, Jalan Raya Bandung-Sumedang Km.21, Jatinangor, Sumedang, Indonesia, Phone: +62 85263862979 Email: aisyah.fahma@ymail.com 
Table 1 Distribution of Postoperative Nausea and Vomiting based on Age

\begin{tabular}{|c|c|c|c|}
\hline Age (Year) & Population (n) & Frequency of PONV & Percentage \\
\hline$<1$ & 9 & $\mathbf{0}$ & $\mathbf{0}$ \\
\hline $1-5$ & 16 & 0 & 0 \\
\hline $6-20$ & 70 & 19 & 27.1 \\
\hline $21-30$ & 54 & 5 & 9.2 \\
\hline $31-60$ & 290 & 64 & 22.1 \\
\hline$>60$ & 82 & 19 & 23.2 \\
\hline Total & 521 & 107 & 20.5 \\
\hline
\end{tabular}

of patients, PONV occurs in recovery room and in $30 \%$ patients 24 hours after surgery. The incidence of PONV varies with many potential causes.This depends on involving anesthetic agents, the type of procedure, and patient factors. ${ }^{2,3,6,10}$

Despite many other studies about PONV in the other regions, the descriptive data about the incidence of PONV in Dr. Hasan Sadikin General Hospital Bandung is still unknown. Considering the huge effects of PONV, this study was aimed to determine the incidence of PONV in Dr. Hasan Sadikin General Hospital Bandung.

\section{Methods}

This cross-sectional descriptive study was conducted in the Department of Anesthesiology and Intensive Care, Dr. Hasan
Sadikin General Hospital Bandung. This study collected and analyzed data from medical records of postoperative patients in Dr. Hasan Sadikin General Hospital Bandung from May $5^{\text {th }}$ to October $31^{\text {st }} 2013$ that were selected by using total sampling method. Inclusion criteria of this study was all the patients who had undergone elective surgery with anesthesia and was in recovery room 2 hours postoperative. Incomplete medical record was excluded from this study.

Data were collected and analyzed based on gender, age, types of surgery, types of anesthesia, duration of surgery, administration of nitrous oxide, and administration of neostigmine.

Secondary data were collected from each subject, then organized and analyzed using descriptive statistical analysis. Frequency and percentage of the mentioned variables were calculated.

Table 2 Distribution of Postoperative Nausea and Vomiting based on Types of Surgery

\begin{tabular}{lccc}
\hline \multicolumn{1}{c}{ Type of Surgery } & Population (n) & Frequency of PONV & Percentage \\
\hline Pediatric surgery & $\mathbf{1 0}$ & $\mathbf{0}$ & $\mathbf{0}$ \\
Digestive Surgery & 125 & 30 & 24.0 \\
Oral Surgery & 35 & 4 & 11.4 \\
Plastic surgery & 39 & 2 & 5.1 \\
Neurological Surgery & 17 & 1 & 5.9 \\
Genitourinary Surgery & 34 & 9 & 26.5 \\
Gynecological Surgery & 92 & 16 & 17.4 \\
Oncology Surgery & 80 & 23 & 28.8 \\
Ortophaedic Surgery & 54 & 11 & 20.4 \\
ENT Surgery & 25 & 9 & 36.0 \\
Thorax and cardiovascular surgery & 10 & 2 & 20.0 \\
Total & 521 & 107 & 20.5 \\
\hline N & & &
\end{tabular}

Note: ENT=Ear Nose and Throat 
Table 3 Distribution of Postoperative Nausea and Vomiting based on Types of Anesthesia

\begin{tabular}{lccc}
\hline \multicolumn{1}{c}{ Type of Anesthesia } & Population (n) & Frequency of PONV & Percentage \\
\hline General Anesthesia & 481 & 96 & 19.9 \\
Regional Anesthesia & 40 & 11 & 27.5 \\
Total & 521 & 107 & 20.5 \\
\hline
\end{tabular}

\section{Results}

In total, 521 postoperative patients were analyzed. Incidence of PONV in Dr. Hasan Sadikin General Hospital Bandung was 20.5\% which occurred on 107 post-operative patients.

The PONV on female $(22.6 \%)$ was 1.3 times more prevalent than male $(17.7 \%)$. PONV was more frequent among patients age 6 to 20 years old $(27.1 \%)$ (Table 1 ).

The Ear Nose and Throat (ENT) surgery was the most frequent cause of postoperative nausea and vomiting (36.0\%), followed by oncology surgery $(28.6 \%)$ and genitourinary surgery $(26.5 \%)$ (Table 2 ).

Patients who had undergone surgery with regional anesthesia, would have a higher risk of PONV (27.5\%)(Table 3).
The highest percentage of postoperative nausea and vomiting based on duration of surgery was on category 181-210 (50.0\%) (Table 4).

Incidence of PONV is higher on patient who have received nitrous oxide $(22.7 \%)$ than those who have not (Table 5).

Incidence of PONV increased among patients who had not received neostigmineand allowed to recover spontaneously from muscular blockade (26.5\%)(Table 6).

\section{Discussions}

The PONV is one of the commonest postoperative complication which sometimes is more disturbing than the operation itself. The complex act of vomiting is controlled by the emetic center in which can be stimulated

Table 4 Distribution of Postoperative Nausea and Vomiting based on Duration of Surgery

\begin{tabular}{lccc}
\hline $\begin{array}{c}\text { Duration of Surgery } \\
\text { (minutes) }\end{array}$ & Population (n) & Frequency of PONV & Percentage \\
\hline$<30$ & 10 & 0 & 0 \\
$30-60$ & 45 & 9 & 20.0 \\
$61-90$ & 17 & 1 & 5.9 \\
$91-120$ & 139 & 21 & 15.1 \\
$121-150$ & 43 & 11 & 25.6 \\
$151-180$ & 145 & 30 & 20.7 \\
$181-210$ & 8 & 4 & 50.0 \\
$211-240$ & 59 & 21 & 35.6 \\
$241-270$ & 2 & 0 & 0 \\
$271-300$ & 18 & 5 & 27.8 \\
$301-330$ & - & - & - \\
$331-360$ & 20 & 2 & 10.0 \\
$361-390$ & 3 & 0 & 0 \\
$391-420$ & 2 & 0 & 0 \\
$421-450$ & - & - & - \\
$451-480$ & 10 & 3 & 30.0 \\
Total & 521 & 107 & 20.5 \\
\hline
\end{tabular}


Table 5 Distribution of Postoperative Nausea and Vomiting based on Anesthesia Inducing Agent

\begin{tabular}{lccc}
\hline \multicolumn{1}{c}{$\begin{array}{c}\text { Agent used for anesthesia } \\
\text { maintenance }\end{array}$} & Population (n) & Frequency of PONV & Percentage \\
\hline Nitrous Oxide & 317 & 72 & 22.7 \\
Without Nitrous Oxide & 204 & 35 & 17.2 \\
Total & 521 & 107 & 20.5 \\
\hline
\end{tabular}

Table 6 Distribution of Post operative Nausea and Vomiting based on Administration of Reverse Muscle Relaxant

\begin{tabular}{lccc}
\hline $\begin{array}{c}\text { Agent used for recover } \\
\text { from muscular blockade }\end{array}$ & Population (n) & Frequency of PONV & Percentage \\
\hline Neostigmine & 404 & 76 & 18.8 \\
Without Neostigmine & 117 & 31 & 26.5 \\
Total & 521 & 107 & 20.5 \\
\hline
\end{tabular}

by several areas, including afferents from pharynx, gastrointestinal tract, mediastinum, as well as afferent from the higher cortical centers and the chemoreceptor trigger zone (CTZ) in the area postrema.,12 There are many surgery procedures and aenesthetic drugs which are able to stimulate the emetic center. ${ }^{7} \mathrm{PONV}$ is influenced by many factors, they are patient, surgical, aenesthetic and postoperative factor. ${ }^{11}$

According to the study's result, theincidence of PONV in Dr. Hasan Sadikin General Hospital Bandung from May $5^{\text {th }}$ to October $31^{\text {st }} 2013$ was $20.5 \%$. Based on literature, incidence of PONV was ranged between $20 \%$ and $30 \%{ }^{8,9}$

Nausea and vomiting in females was about 1.3 times as common as in males. Koivuranta et al. ${ }^{14}$ reported that the proportion of females was about twice as male and men are generellay less succeptible to nausea. ${ }^{10,12}$ Based on other studies, female sex was an important risk factor for PONV that maybe caused by variations in serum gonadotropin or other hormon levels. Some studies were even concerned with the relationship of PONV and phase of menstrual cycle. Particularly, female who is on $3^{\text {rd }}-4^{\text {th }}$ week of their menstruation cycles was more tend to experience PONV caused by changing and high level of progesteron, estrogen and gonadotropin hormone level. ${ }^{8,11,12}$ Furthermore, female who undergone gynecology surgery increase the risk of PONV caused by stimulation of afferents in uterus, broad ligament and cervix..$^{15}$

Incidence of PONV was higher in category age 6-20 years old. Based on theories, the percentage of PONV on patient's age that is less than 12 months is low. Infant and adolescent patients have an increased risk PONV. PONV decreases as patient age. It is unclear whether this resulted purely from age itself or difference of aenesthetic drugs used and surgical procedure performed. ${ }^{7}$

In the present study, there was variation in the incidence of PONV based on the type of surgery. The study results showed that the highest percentage of PONV was on category of ENT surgery, followed by the patients with oncological surgery, and genitourinary surgery. According to the literature, the procedure on middle ear will stimulate vestibular afferent nerve that will stimulate the vomiting center ${ }^{7,8,10,11}$

Despite the high incidence of PONV in surgeries mentioned earlier, PONV was also common in patients with digestive surgery, and ortophaedic surgery. It has to be noted that the emetic center is stimulated by several visceral afferents including digestive tract, and manipulation in this area could activate gastrointestinal responses. ${ }^{1,7,10}$ Also, laparoscopy was one of the procedure performed in digestive surgery. Based on the references, laparoscopic surgeries was known to be a risk of PONV. It might be due to increase in carbondioxide absorbtion into the intestine and increase intraabdominal pressure. ${ }^{11}$ Another literature showed that incidence of PONV was also high in orthopaedic procedure, but the mechanism was still unclear.

This study results revealed that patients who received regional anesthesia were more 
likely to experience PONV than patients with general anesthesia. Meanwhile, a study conducted by Aftab et al. ${ }^{13}$ in Karachi reported that patients who received general anesthesia experienced three times more incidence of PONV, compared to regional anesthesia. This differences might be due to the limitation of the study.

According to the study results, the highest percentage of PONV based on duration of surgery was on category 181-210 minutes $(50.0 \%)$. The study conducted by Ku et al. ${ }^{8}$ in Singapore reported that the incidence of PONV was $2.7 \%$ in surgery with duration less than 30 minutes, and $27.7 \%$ in patients with operation lasting 150-180 minutes. This possibilities might happen because in long duration of surgery, patient received larger number of potentially emetic drug. ${ }^{7}$

In this study, incidence of PONV in patients receiving nitrous oxideas anesthetic maintenance is $5.5 \%$ higher than who did not. This was similar to the study conducted by Doubravska et al. ${ }^{11}$ which noted that the incidence of PONV innitrous oxide were higher than those not (15.8\% vs $2.4 \%$ ). Earlier study suggested that nitrous oxide causes stimulation of the medullary periventricular dopaminergic system, which includes the CTZ, and this could be responsible for the nausea and vomiting observed after nitrous oxide anaesthesia. $^{8}$

According to the study results, the incidence of PONV in patients receiving neostigmine as muscle relaxant and patients who spontaneously recovered from muscular blockade were $18.8 \%$ and $26.5 \%$ respectively, while the study conducted by Kim et al. ${ }^{15}$ reported that patients treated with neostigmine had higher rates of PONV (68\% vs $32 \%)$.This discrepancy may attributable due to the limititation of the study.

From 521 respondents who had undergone elective surgery with anesthesia at the Dr. Hasan Sadikin General Hospital, 20.5\% experienced postoperative nausea and vomiting. Female has the highest incidence based on gender. Patients aged 6-20 years old, patients with ENT, oncological and genitourinary surgery had an increased risk of PONV. Based on category of anesthesia, PONV in patients receiving regional anesthesia was more common. Based on duration of surgery, category 181-210 minutes was the highest duration on the incidence of PONV. The PONV was more prevalent to patients receiving nitrous oxide than those who did not. Patients who were given neostigmine as reverse muscle relaxant had a lower incidence of PONV than the patients who recovered spontaneously.

Reccomendation of this study is about data completeness in medical record should be corrected. Many incomplete data made difficult to find the exact result.

To know more about PONV, for further research, it needs to be conducted with larger population and more variable included.

\section{References}

1. McCracken G, Houston P, Lefebvre G. Guideline for the management of postoperative nausea and vomiting. J Obstet Gynaecol Can. 2008;30(7):600-7.

2. Finks JF. Complication of Laparoscopic Surgery. In: Mulholland MW, Doherty GM, editors. Complication in Surgery. 2nd ed. Philadelphia: Lippincott William \& Wilkins; 2011. p. 529.

3. Fowler MA, Spiess BD. Post Anesthesia Recovery. In: Barash, G. P, Cullen, F B, editors. Clinical Anesthesia. 6th ed. Philadelphia: Lippincott William \& Wilkins; 2009. p. 1441.

4. Apfel CC, Korttila K, Abdalla M, Kerger H, Turan A, Vedder I, et al.. A factorial trial of six interventions for the prevention of postoperative nausea and vomiting. N Engl J Med. 2004;350(24):2441-51.

5. Riad W, Marouf H. Combination therapy in the prevention of PONV after strabismus surgery in children: granisetron, ondansetron, midazolam with dexamethasone. Middle East J Anesthesiol. 2009;20(3):431-6.

6. Mansour, Nassef A, Moussa MA, Ashraf A. Effect of preoperative hydration on postoperative nausea and vomiting. Bull Alex Fac Med. 2007;43(4):1037-41.

7. Islam S, Jain PN. Post-Operative Nausea Vomiting (PONV): a review article. Indian J Anaesth. 2004;48(4):253-8.

8. Norred CL. Antiemetic prophylaxis: pharmacology and therapeutic. AANA J. 2003;71(2):133-40.

9. Chatterjee S, Rudra A, Sengupta S. Current concepts in the management of postoperative nausea and vomiting. Anesthesiol Res Prac. 2011;2011:748031.

10. Doubravska L, Dostalova K, Fritscherova S, Zapletalova J, Adamus M. Incidence of postoperative nausea and vomiting in patients at a university hospital. where are we today? Biomed Pap Med Fac Univ Palacky Olomouc Czech Repub. 2010;154(1):69-76. 
11. Ku CM, Ong BC. Postoperative nausea and vomiting : a review of current literature. Singapore Med J. 2003;44(7):366-74.

12. Apfel CC. Postoperative nausea and vomiting. In: Miller RD, editor. Miller's Anesthesia. 7th ed. California: Elsevier; 2005. p. 86.

13. East JM, Mitchell DI. Postoperative nausea and vomiting in laparoscopic versus open cholecystectomy at two major hospital in Jamaica. West Indian Med J. 2009;58(2):130-7.
14. Kim S, Shin Y, Oh Y, Lee J, Ching S, Choi Y. Risk assessment of postoperative nausea and vomiting in the intravenous patientcontrolled analgesia environment: predictive values of the Apfel's simplified risk score for identification of high-risk patients. Yonsei Med J. 2013;54(5):1273-81.

15. Aftab S, Khan AB, Raza G. The assessment of risk factors for postoperative nausea and vomiting. J Coll Physicians Surg Pak. 2008;18(3):137-41. 